\title{
AVALIAÇÃO DO USO DE FERRAMENTAS FINANCEIRAS NA PRÁTICA DE GESTÃO DAS EMPRESAS DO SETOR DE VENDAS DE MATERIAL DE CONSTRUÇÃO E FERRAGENS ${ }^{1}$
}

\section{EVALUATION OF THE USE OF FINANCIAL TOOLS IN PRACTICE OF MANAGEMENT IN COMPANIES IN THE THE SALES SECTOR OF CONSTRUCTION MATERIALS AND HARDWARE}

\section{EVALUACIÓN DEL USO DE HERRAMIENTAS FINANCIERAS EN LA PRÁCTICA DE GESTIÓN DE EMPRESAS DE LO SECTOR DE VENTAS DE MATERIALES DE CONSTRUCCIÓN Y HARDWARE}

\begin{abstract}
Bruno César de Melo Moreira, Doutor em Administração pela Universidade Federal de Santa Catarina (UFSC). Endereço Profissional: Instituto Federal de Minas Gerais (IFMG), Campus Formiga. R. Padre Alberico, 440 - São Luiz, Formiga, MG - Brasil, CEP 35570-000. Telefone: (037) 3322-8428. URL da Homepage: www.formiga.ifmg.edu.br. E-mail: bruno.melo@ifmg.edu.br.
\end{abstract}

Natália Aparecida Gondim Ferreira, Tecnóloga em Gestão Financeira (IFMG). Endereço Profissional: Instituto Federal de Minas Gerais (IFMG), Campus Formiga. R. Padre Alberico, 440 São Luiz, Formiga, MG - Brasil, CEP 35570-000. Telefone: (037) 3322-8428. URL da Homepage: www.formiga.ifmg.edu.br. E-mail: tatagferreira@yahoo.com.br.

Daniel Fonseca Costa, Doutorando em Administração pela Universidade Federal de Lavras (UFLA). Endereço Profissional: Instituto Federal de Minas Gerais (IFMG), Campus Formiga. R. Padre Alberico, 440 - São Luiz, Formiga, MG - Brasil, CEP 35570-000. Telefone: (037) 3322-8428. URL da Homepage: www.formiga.ifmg.edu.br.

\section{RESUMO}

Nos últimos anos, o setor de vendas de material de construção e ferragens tem vivenciado uma forte queda em seu volume de vendas, muito guiado pelo próprio desaquecimento do setor de construção civil (GONÇALVES, 2014). Associado ao delicado momento vivenciado pelo país, a acirrada competição com produtos importados, limitação de capital, estrutura administrativa enxuta e, muitas vezes, sem conhecimentos técnicos suficientes, tem impossibilitado, na maioria dos casos, que as empresas do setor apresentem uma administração financeira eficaz e consigam se manter no mercado. Em Formiga, cidade situada no centro-oeste de Minas Gerais, a situação também não se encontra diferente. Com aproximadamente 23 empresas no setor de vendas de materiais para construção e ferragens, todas de micro ou pequeno porte, o segmento vem sofrendo uma queda em suas vendas e, consequentemente em seu faturamento (FUNDAÇÃO JOÃO PINHEIRO, 2016). Sob este contexto, o objetivo do presente trabalho é verificar se as empresas do setor de venda de material de construção e ferragens da cidade de Formiga utilizam ferramentas financeiras em sua prática de gestão. Entende-se que, um dos diferenciais para que as mesmas consigam se manter competitivas, é que apresentem boas práticas de administração financeira. Para tanto, a metodologia empregada caracteriza-se como um survey, utilizando-se de um questionário, baseado em Cunha (2002), como método de coleta de dados. Os resultados mostraram que os gestores/administradores encontram dificuldades como falta de informações coerentes e reais, além de despreparo para a

\footnotetext{
${ }^{1}$ Artigo submetido em 27/07/2016, revisado em 29/08/2016, aceito em 29/12/2016 e divulgado em 01/07/2017 pelo Editor João Carlos Hipólito Bernardes do Nascimento, após double blind review.
} 
interpretação dos relatórios e incapacidade de obter vantagem competitiva por meio do uso eficiente da administração financeira.

Palavras-chave: Administração Financeira; Demonstrações Financeiras; Construção Civil.

\begin{abstract}
In recent years, the sales sector of construction materials and hardware has experienced a sharp drop in their sales volume, much driven by own slowdown of the construction sector. Associated with the delicate moment experienced by the country, the fierce competition with imported products, limited capital, lean administrative structure and often without sufficient technical knowledge, has made impossible, in most cases, to companies in the sector presents an effective financial management and able to remain on the market. In Formiga, a city in the Midwest of Minas Gerais state, the situation is also not different. With approximately 23 companies in the sales sector of construction materials and hardware, all micro or small, the segment has suffered a drop in sales and consequently in its revenues. In this context, the objective of this study is to verify that the companies of the sales sector of construction materials and hardware in Formiga City uses financial tools in their management practice. It is understood that one of the differences so that they are able to remain competitive is to have good financial management practices. Therefore, the methodology is characterized as a survey, using a questionnaire based on Cunha (2002), as a data collection method. The results showed that managers/administrators encounter difficulties such as lack of real and consistent information, as well as preparation for the interpretation of reports and inability and unpreparedness for the interpretation of reports and inability to gain competitive advantage through efficient use of financial management.
\end{abstract}

Keywords: Financial Management; Financial Statements; Construction.

\title{
RESUMEN
}

En los últimos años, el sector de ventas de materiales de construcción y hardware ha experimentado una fuerte caída en su volumen de ventas, impulsado por la propia desaceleración de la industria de la construcción (Gonçalves, 2014). Asociado con el delicado momento que vive el país, la feroz competencia con los productos importados, capital limitado, la estructura administrativa magra y muchas veces sin los conocimientos técnicos suficientes, no puede, en la mayoría de los casos, las empresas del sector presentan una gestión financiera eficaz y capaz de permanecer en el mercado. En la hormiga, una ciudad en la región central de Minas Gerais, la situación tampoco es diferente. Con aproximadamente 23 empresas del sector de la venta de materiales de construcción y ferretería, todos los micro o pequeñas, el segmento ha sufrido una caída en las ventas y por lo tanto en su volumen de negocios (Fundación João Pinheiro, 2016). En este contexto, el objetivo de este estudio es verificar que las empresas de venta de la industria de materiales de construcción y ferretería Formiga City utilizando herramientas financieras en sus prácticas de gestión. Se entiende que una de las diferencias de modo que sean capaces de mantener su competitividad es tener buenas prácticas de gestión financiera. Por lo tanto, la metodología se caracteriza por ser una encuesta, utilizando un cuestionario basado en Cunha (2002), como un método de recolección de datos. Los resultados mostraron que los gerentes / administradores dificultades como la falta de información consistente y real, y la falta de preparación para la interpretación de los informes y la incapacidad para obtener una ventaja competitiva a través del uso eficiente de la gestión financiera.

Palabras-clave: Gestión financiera; Demostraciones financieras; Construcción civil.

\section{INTRODUÇÃO}

administração financeira consiste no uso de ferramentas que permitem identificar
oportunidades, corrigir erros, fornecer informações que auxiliam na otimização dos
recursos disponíveis para o crescimento da empresa. A partir de uma boa

GєCont, v. 4, n. 1, Floriano-PI, Jan-Jun. 2017. 
administração financeira é possível aumentar a rentabilidade da empresa e, como consequência, aumentar o lucro dos proprietários das organizações. A falta da utilização desta prática pode comprometer a estrutura organizacional, fazendo com que a empresa não atinja os resultados esperados, prejudicando sua evolução, principalmente em setores mais dinâmicos da economia (CUNHA, 2002) e nas Micro e Pequenas Empresas (MPEs) que adotam uma administração financeira geralmente focada no curto prazo, com ênfase apenas na gestão do caixa (PLÁCIDO; SANTOS; MURTA, 2015).

Tal situação pode ser observada no setor de vendas de materiais para construção e ferragens construção civil. Guiada pelo "boom" do setor de construção civil, com forte crescimento a partir de 2005, a indústria de materiais para construção e ferragens apresentou considerável crescimento, com média de $10 \%$ ao ano entre 2005 e 2009 (DIEESE, 2013).

Em Formiga, cidade situada na região centro-oeste de Minas Gerais, o setor de construção civil também apresentou destaque em que, para os anos de 2005 a 2011 apresentou um crescimento de $453 \%$, superior à média nacional. Neste mesmo período as vendas de material de construção civil mais que duplicaram, alcançando um crescimento de $263 \%$ (FUNDAÇÃO JOÃO PINHEIRO, 2016).

No entanto, apesar do expressivo crescimento do setor no período passado, de 2011 para 2012, a construção civil apresentou uma queda de 11,76\% em suas atividades (FUNDAÇÃO JOÃO PINHEIRO, 2016) repercutindo no segmento de vendas de material de construção e ferragens. Segundo Gonçalves (2014), nos últimos anos, foi possível observar que o ritmo de crescimento no setor está diminuindo e que a importação tem aumentado. Em 2016 há uma perspectiva de retração no volume de vendas com a manutenção de condições negativas vistas em 2015 (ABRAMAT, 2015).

Além disso, a crescente e acirrada competição com produtos importados, a limitação de capital, a estrutura administrativa enxuta e, muitas vezes, sem conhecimentos técnicos suficientes e a falta de uma gestão profissional têm impossibilitado, na maioria dos casos, que as micro, pequenas e médias empresas apresentem uma administração financeira eficaz (CUNHA, 2002).

Em Formiga, a situação também não se encontra diferente. Com aproximadamente 23 empresas no setor de vendas de materiais para construção e ferragens, todas de micro ou pequeno porte, o segmento vem sofrendo uma queda em suas vendas e, consequentemente em seu faturamento (FUNDAÇÃO JOÃO PINHEIRO, 2016).

Sob este contexto, o objetivo do presente trabalho é verificar se as empresas do setor de venda de material de construção e ferragens da cidade de Formiga utilizam ferramentas financeiras em sua prática de gestão.

Ressalta-se que, devido a importância do tema, principalmente nos últimos anos em que diversas MPEs estão fechando em decorrência da crise econômica que o país vivencia, diversos trabalhos têm se dedicado a analisar esta temática em empresas de diversos setores e regiões do país. (CUNHA, 2002; LIMA; IMONIANA, 2008; SOARES et al., 2010; FERNANDES; GONÇALVES, 2011; FARIA; OLIVEIRA; AZEVEDO, 2012; CASALI, 2015; MARTINS, 2015; MIRANDA et al., 2015; RODRIGUES; MELO; LEONE, 2016). Nestes moldes, o presente trabalho optou por utilizar a metodologia proposta por Cunha (2002), por ser a mais abrangente e que possibilita capturar maiores nuances do uso das ferramentas de administração financeira. No entanto, de maneira semelhante aos estudos de Miranda et al. (2015) e Rodrigues, Melo e Leone (2016), optou-se, também, por abordar o setor mais dinâmico da economia da cidade alvo do estudo.

Neste sentido, este trabalho se justifica dado a importância do setor para a economia da cidade e região, bem como o potencial de se desenvolver ações efetivas como o incentivo à adoção de boas práticas de administração financeira por parte destas empresas, como forma de se manterem competitivas e permanecerem no mercado. 


\section{REFERENCIAL TEÓRICO}

\subsection{A ADMINISTRAÇÃO FINANCEIRA EM MICRO E PEQUENAS EMPRESAS}

O uso da administração financeira pode ter variação de acordo com os gestores e tamanho da empresa. Em empresas de pequeno porte, a função financeira geralmente é desenvolvida pelo departamento de contabilidade. Com o desenvolvimento da empresa, essa função passa a ser exercida em departamentos separados e ligados diretamente ao presidente da empresa, com supervisão do diretor financeiro (GITMAN, 2010).

Conforme Viapiana (2000), as empresas de pequeno porte têm um papel importante na economia dos países, tendo a responsabilidade de gerar empregos e distribuir renda, além de ter uma participação considerável no PIB. Uma observação do autor é que mesmo as MPEs representando importante papel para a economia do país, é possível observar que essas enfrentam inúmeros problemas. Esses problemas podem ser internos ou externos e nem sempre são identificados pelos gestores. Com isso, muitas não conseguem superar as dificuldades, encerrando, assim, suas atividades.

Para Assaf Neto (2010), dentro de uma empresa, a administração financeira baseia-se nas seguintes funções: gerenciamentos de passivo e ativo e planejamento e controle financeiro. Para Lemes Jr. (2005), a administração financeira possui as funções de planejamento, orçamento, fluxo de caixa, investimentos, financiamentos, crédito, cobrança, operações bancárias, entre outros.

Dentre as ferramentas da administração financeira, está o processo de planejamento e gerenciamento de investimentos a longo prazo que é definido por Ross (2008) como orçamento de capital. Ainda segundo o autor, nessa função, o gestor financeiro identifica oportunidades de investimento que tenham valor superior a seu custo de aquisição. Para Caravantes (2005), a falta de planejamento ou um planejamento feito de forma precária pode ter consequências graves para as empresas.

Outra ferramenta da administração financeira é o orçamento de caixa, que é a demonstração das entradas e saídas de caixa prevista pela organização (GITMAN, 2010). O orçamento de caixa é utilizado para calcular as necessidades de caixa no curto prazo, dando atenção ao planejamento de superávits e déficits de caixa e, geralmente, abrange o período de doze meses. Assim, para que a empresa possa fazer um orçamento de caixa é importante que desenvolva um processo de análise permanente das tendências do mercado, visando observar mudanças configuradas em outros cenários, já definidas ou não. Com isso, as previsões são importantes para que a organização tenha conhecimento de quais decisões devem ser tomadas, caso tenha alguma alteração no cenário econômico, e, assim, prosseguir em direção à visão estabelecida anteriormente (CARAVANTES, 2005). Neste sentido, o orçamento deve ser construído a partir da previsão de vendas, estando ligado com o planejamento e servindo de controle para a decisão de como os gastos serão realizados (GUPTA, 2013).

De uma forma mais abrangente, autores como Costa (2014), Costa et al. (2014) e Silva, Santos e Costa (2016) tem demonstrado, em seus trabalhos, os benefícios do orçamento para a gestão empresarial. Esses autores discutem que a previsão orçamentária pode ser útil para a tomada de decisões.

Além do orçamento de caixa, outra ferramenta utilizada é o fluxo de caixa, definido por Santos (2010) como um mecanismo de planejamento financeiro que objetiva fornecer estimativas da situação de caixa da empresa em determinado período de tempo. Para Camargo (2007), a demonstração do fluxo de caixa analisa todos os acordos empresariais que alteram o caixa da empresa, observando a origem dos recursos disponíveis, onde estes foram utilizados e qual o resultado do fluxo financeiro da empresa. 
Assim, as decisões de investimento são importantes para a empresa por envolverem valores significativos que, normalmente, possuem um objetivo de longo prazo (SANTOS, 2010). A finalidade da análise de investimento é a de obter uma alternativa de ação ou a de escolher a mais interessante entre várias, por meio da utilização de métodos quantitativos. Já as decisões de financiamento são definidas como as que relacionam a escolha da estrutura de capital, a determinação do custo de capital e a captação de recursos (LEMES JÚNIOR, 2005). Além disso, essas decisões influenciam na definição das fontes de financiamento a serem usadas nas operações da empresa e nos projetos de investimento, que podem se originar de capital próprio ou de capital de terceiros (ASSAF NETO, 2010).

A administração de ativos da empresa, para Assaf Neto (2010), deve buscar a melhor estrutura, em termos de risco e retorno dos investimentos empresariais, e proceder a uma administração eficaz de seus valores. Já a administração de passivos, que se vale da obtenção de fundos (financiamento) e o gerenciamento de sua formação, busca definir a estrutura mais certa em termos de liquidez, redução de custos e risco financeiro. O gerenciamento de risco em uma empresa pode ser conceituado como a união de todas as pessoas, procedimentos e sistemas utilizados para controlar as perdas possíveis dos fundos de investimentos (DUARTE JÚNIOR, 2005). Diante disso, o balanço patrimonial mostra, em dado momento, tudo o que a empresa tem de bens e direitos a receber, o valor que ela deve a terceiros e o montante de capital investido pelos proprietários (CAMARGO, 2007).

Ademais, a demonstração dos resultados das empresas evidencia, de forma organizada, os componentes que causaram mudanças no patrimônio líquido das mesmas (ATHAR, 2005). Para o autor, trata-se de um demonstrativo ordenado das receitas, despesas e custos que fornece aos administradores da organização dados básicos da formação do resultado, demonstrando, assim o lucro ou o prejuízo auferido.

Além disso, medidas como a liquidez e margem de contribuição são importantes para a gestão da empresa. A liquidez de uma organização é mensurada em termos de sua capacidade de quitar suas obrigações de curto prazo à medida que se tornam devidas (GITMAN, 2010). A liquidez refere-se à solvência da posição financeira geral da organização e a maneira com que se pode pagar as contas em dia. Para Rodrigues (2011), os índices de liquidez apresentam importância pelo fato de que eles manifestam se a empresa possui bens ou direitos capazes de realizar o pagamento de todas as obrigações oriundas da obtenção de recursos através de terceiros: fornecedores, bancos, funcionários e governo.

Já a margem de contribuição é definida como a diferença entre o preço de venda e os custos variáveis para cada unidade vendida do produto (ROCHA, 2012). Segundo Ferreira (2007), por meio da margem de contribuição, pode-se analisar a viabilidade de determinado produto. Se esse indicador for positivo, a produção daquele item é viável, caso seja igual a zero ou negativo, o produto não oferece benefícios à organização. Ainda segundo o autor, por meio da margem de contribuição pode-se encontrar o ponto de equilíbrio, que representa o momento em que o nível de vendas supre todos os gastos de investimento em um projeto. Para Camargo (2007), o ponto de equilíbrio verifica a relação entre custos, volume de produção e lucros empresariais, admitindo a compreensão de como o lucro pode ser alterado pelas oscilações nas receitas de vendas, nos custos ou nas despesas totais.

Em um survey a respeito do assunto, Cunha (2002) objetivou verificar se pequenas e médias empresas brasileiras de todos os setores utilizavam os conhecimentos aplicados nas rotinas administrativas. A pesquisa foi realizada por meio de questionários. Os resultados demonstraram que as pequenas empresas apresentavam grandes problemas na administração. Ainda foi possível perceber que as médias empresas apresentavam uma melhora na sua gestão. Cunha (2002) verificou que as pequenas empresas têm a possibilidade de apresentar uma administração financeira adequada, porém o número de empresas ineficientes é grande.

Especificamente no setor de comércio de materiais de construção, Faria, Oliveira e Azevedo (2012) buscaram analisar como ocorre o uso da contabilidade enquanto instrumento de apoio à gestão nas micro e pequenas empresas no município de Feira de Santana - BA. Os resultados 
alcançados pelo estudo demonstraram que, dado a característica das empresas do setor nesta cidade, em que se destaca: empresas em sua maioria de micro e pequeno porte, com quase $70 \%$ dos proprietários como gerentes, sendo que $66 \%$ possuíam no máximo o ensino médio completo, em geral, as empresas apresentaram baixo conhecimento e uso das ferramentas de administração financeira (com foco nas informações contábeis) para o apoio à tomada de decisão.

Por sua vez, também com o foco em empresas de todos os setores, mas restringindo-se ao município de São Caetano do Sul, Lima e Imoniana (2008) objetivaram evidenciar o uso das ferramentas de controle gerencial que auxiliam no processo de tomada de decisão nas MPEs. Os resultados alcançados pelos autores demonstraram que, em decorrência da formação técnica dos gestores da empresa (mais de $53 \%$ possuiam curso superior ou pós-graduação) e da aplicação prática destes conhecimentos, as decisões, na maioria das empresas analisadas, eram orientadas pelo uso significante das ferramentas de administração financeira.

Fernandes e Gonçalves (2011) avaliaram o perfil da gestão financeira realizada pelas MPEs da cidade de Itajubá, com foco a evidenciar os principais condicionantes da mortalidade das empresas na cidade. Os autores perceberam nas empresas analisadas é que apenas $20 \%$ das mesmas possuiam um funcionário específico para gerir as finanças da organização, e que a falta de conhecimento e uso das ferramentas de gestão financeira eram fatores primordiais para deficiência na administração financeira apresentada pelas empresas.

Objetivando realizar um diagnóstico da gestão financeira nas microempresas da cidade de Cruz Alta/RS, Casali (2015) abordou o tema da administração financeira e as funções do administrador financeiro nas empresas avaliadas. De forma contrária ao encontrado por Lima e Imoniana (2008), os resultados apontam que, em Cruz Alta, a maioria dos gestores não possuíam formação técnica na área e que, mesmo utilizando de algumas ferramentas de controle e planejamento financeiro, as empresas sofriam de diversas limitações, principalmente na falta de conhecimento e uso mais generalizado de tais ferramentas.

Outro estudo correlato foi realizado por Soares et al. (2010), cujo objetivo foi verificar se as empresas moveleiras faziam o uso das ferramentas da administração financeira, além de demonstrar as vantagens da utilização das mesmas. Soares et al. (2010), pôde concluir que a maioria das empresas utiliza as ferramentas para gerir o empreendimento. O estudo demonstrou, de forma clara, como as ferramentas da gestão financeira são importantes para a sua maximização de lucros. De acordo com os dados analisados, pode-se perceber que a administração financeira fornece meios eficientes e eficazes na obtenção de resultados positivos por parte da empresa.

Em se tratando de avaliar o uso de ferramentas financeiras por partes das empresas, Martins (2015) e Miranda et al. (2015) também abordaram esta temática. Martins (2015) buscou avaliar, junto às MPEs da cidade de Pato Branco - PR, quais as ferramentas de gestão financeira são utilizadas como forma de auxílio pelos empresários no controle e tomada de decisão. Analisando empresas de todos os setores na cidade, a autora detectou que as MPEs avaliadas faziam uso de algum tipo de ferramenta de gestão financeira (controle de contas a pagar e a receber, controle bancário, controle de despesas, controle de estoque, entre outros) como auxilio no controle dos seus processos e tomada de decisão. No entanto, a falta de conhecimento, bem como o interesse dos gestores em aprofundar no uso de tais ferramentas se mostrou fato preocupante, o que na opinião da autora, tem impactado na sobrevivência destas empresas no mercado.

Já em seu estudo, Miranda et al. (2015) buscaram analisar as principais ferramentas gerenciais utilizadas pelas MPEs do setor de comércio da cidade de Viçosa-MG. Os achados também apontam que a utilização das ferramentas financeiras no auxílio do gerenciamento e tomada de decisões é, em geral, muito baixa ou até mesmo nula em algumas das empresas. Os 
autores ressaltam que apenas o fluxo de caixa e remuneração por competência se mostraram como ferramentas utilizadas por parcela considerável das empresas analisadas.

\section{O SETOR VAREJISTA DE MATERIAL DE CONSTRUÇÃO}

\subsection{PRINCIPAIS CARACTERÍSTICAS, EVOLUÇÃO E TENDÊNCIA}

De acordo com dados da Associação Nacional dos Comerciantes de Material de Construção - Anamaco (2006), o Brasil possui, aproximadamente, 138 mil lojas, sendo que mais de 60\% delas estão no mercado há mais de dez anos.

Segundo dados do Serviço Brasileiro de Apoio às Micro e Pequenas Empresas - SEBRAE (2013), a taxa de sobrevivência das empresas do setor de construção com dois anos, representa em média, $72,5 \%$, sendo que o maior percentual foi na região sudeste com $77,3 \%$ e a menor taxa observada foi na região norte com 56,3\%. Com relação aos anos anteriores, a taxa de sobrevivência do setor teve um aumento representativo (cerca de nove pontos percentuais). A este crescimento pode ser atribuído o fato do aumento da demanda interna por este ramo, além de uma melhora na qualidade dos produtos e serviços do setor.

Para o Dieese (2013), o setor de construção civil representou 5,7\% do Produto Interno Bruto (PIB) em 2012. Este valor foi obtido por meio das várias formas de incentivos para o setor, como criação de obras de infraestrutura e unidades habitacionais por parte do governo federal, a fim de estimular o gasto com produtos e a geração de empregos. Em Minas Gerais, de acordo com o IBGE (2014), o ramo de construção civil possuía, no ano de 2011, cerca de 6.437 empresas, gerando emprego para 334.122 pessoas e com receita líquida em média de $\mathrm{R} \$ 32,5$ bilhões.

De acordo com Associação Brasileira da Indústria de Materiais de Construção ABRAMAT (2015) no ano de 2013, a cadeia produtiva da construção gerou um valor adicionado de R \$ 349,2 bilhões e quase 14 milhões de ocupações em todo o País. Foram consumidos R \$ 368,1 bilhões em bens e serviços. Em 2013, o número de posto de trabalho na indústria de materiais de construção chegou a 826 mil, com crescimento de $0,7 \%$ em relação à 2012. As vendas de materiais de construção pelo comércio tiveram alta de $5 \%$.

Já no ano de 2014, o setor de construção civil apresentou um crescimento inferior a $2 \%$. Campelo Jr. e Tobler (2014) expõem que dentre os fatores apontados pelas empresas como limitadores ao investimento produtivo estão: as incertezas em relação à demanda (escolhidas por $38,8 \%$ das empresas), a limitação de recursos $(38,7 \%)$, a limitação de crédito $(37,1 \%)$ e a carga tributária elevada $(31,8 \%)$. Esses fatores podem ser comprovados por meio do Indicador de Confiança da Construção que, no primeiro bimestre, estava abaixo do nível médio dos três anos anteriores e dez pontos abaixo da média para este período do ano.

De acordo com o Centro de Excelência em varejo da FGV - EAESP (2012), a maior parte do consumo de materiais de construção é realizado pelas famílias, que representam cerca de $49 \%$ do consumo, em segundo lugar encontram-se as construtoras com $35 \%$ do consumo e, em seguida, as indústrias com $16 \%$.

\section{PROCEDIMENTOS METODOLÓGICOS}

\subsection{CLASSIFICAÇÃO}

A pesquisa realizada será do tipo quantitativa que, de acordo com Mascarenhas (2012), baseia-se na quantificação para coletar e, mais tarde, tratar os dados obtidos. Neste tipo de pesquisa, é fundamental usar técnicas estatísticas como porcentagens, médias e desvio padrão.

Para a coleta de dados, foi utilizado um questionário com trinta perguntas, relacionadas com a administração financeira das empresas do setor de materiais de construção da cidade de Formiga. 


\subsection{AMOSTRA}

A amostra será composta por empresas sediadas na cidade de Formiga (MG) cujo segmento de atividade é a venda a varejo de material de construção. As empresas serão escolhidas de forma não aleatória, buscando representar dados mais próximos possíveis da realidade. A cidade conta com 23 empresas do setor de materiais de construção e ferragens. Deste total, não foram entrevistados os depósitos que comercializam apenas materiais como areia, brita e tijolos, lojas de tinta, pelo fato de possuírem estrutura diferenciada das demais empresas entrevistadas.

Ressalta-se que, do total de empresas, apenas 12 das empresas responderam ao questionário.

\subsection{DETALHAMENTOS DO QUESTIONÁRIO}

O questionário utilizado possui trinta perguntas e foi delineado baseado no proposto por Cunha (2002). As perguntas foram feitas para os donos/administradores das empresas e estão relacionadas à contabilidade, administração financeira aprofundada, tesouraria, auto avaliação, custos, demonstrações financeiras, fluxos de caixa, outros temas e dificuldades na implantação da administração financeira.

As perguntas do questionário são apresentadas e divididas por segmentos, conforme Quadro 1 e o questionário disposto no Apêndice A.

\begin{tabular}{|c|c|c|}
\hline Tema & Questões & Justificativa \\
\hline \multirow{8}{*}{ Tesouraria } & 2 & \multirow{8}{*}{$\begin{array}{l}\text { As questões } 2,3,4,5,15,18,19 \text { e } 20 \text {, referem-se à } \\
\text { tesouraria. Busca indicar se as empresas possuem } \\
\text { relatórios para controle e gerenciamento das atividades } \\
\text { de rotina. Além disso, mostra quais mecanismos e } \\
\text { relatórios são utilizados pelas organizações. }\end{array}$} \\
\hline & 3 & \\
\hline & 4 & \\
\hline & 5 & \\
\hline & 15 & \\
\hline & 18 & \\
\hline & 19 & \\
\hline & 20 & \\
\hline \multirow{4}{*}{ Demonstrações Financeiras } & 6 & \multirow{4}{*}{$\begin{array}{l}\text { As perguntas } 6,7.16 \text { e } 17 \text { fazem referências às } \\
\text { demonstrações financeiras. Indicam se as empresas } \\
\text { utilizam relatórios para controle financeiro das } \\
\text { empresas. }\end{array}$} \\
\hline & 7 & \\
\hline & 16 & \\
\hline & 17 & \\
\hline Contabilidade & 8 & $\begin{array}{l}\text { A questão } 8 \text { é ligada à contabilidade. Demonstra qual } \\
\text { a periodicidade em que os balancetes contábeis são } \\
\text { analisados e mostra se estes relatórios são importantes } \\
\text { para a empresa ou se possuem apenas utilidade para } \\
\text { fins fiscais. }\end{array}$ \\
\hline \multirow{5}{*}{ Auto Avaliação } & 1 & \multirow{5}{*}{$\begin{array}{l}\text { As perguntas } 1,26,27,28,29 \text { relatam sobre a auto } \\
\text { avaliação. Demonstram como as empresas se } \\
\text { classificam diante de sua situação financeira, margem } \\
\text { de lucro, retorno sobre investimento e administração } \\
\text { financeira em geral. }\end{array}$} \\
\hline & 26 & \\
\hline & 27 & \\
\hline & 28 & \\
\hline & 29 & \\
\hline \multirow{6}{*}{$\begin{array}{c}\text { Administração Financeira } \\
\text { Aprofundada }\end{array}$} & 9 & \multirow{6}{*}{$\begin{array}{l}\text { As questões } 9,10,11,12,13 \text { e } 14 \text {, são ligadas à } \\
\text { administração financeira aprofundada. Demonstram se } \\
\text { as empresas usam relatórios para verificar a } \\
\text { viabilidade de investimentos, projeções para } \\
\text { acompanhamento da situação financeira além da } \\
\text { utilização de índices para avaliar seu desempenho. }\end{array}$} \\
\hline & 10 & \\
\hline & 11 & \\
\hline & 12 & \\
\hline & 13 & \\
\hline & 14 & \\
\hline
\end{tabular}




\begin{tabular}{|c|c|c|}
\hline Custos & 21 & $\begin{array}{l}\text { A pergunta } 21 \text { refere-se aos custos. Considera se as } \\
\text { empresas utilizam custos como taxa de juros, despesas } \\
\text { com cobranças na formação do preço de venda a } \\
\text { prazo. }\end{array}$ \\
\hline Fluxo de caixa & 22 & $\begin{array}{l}\text { A questão } 22 \text { vem demonstrar o fluxo de caixa. Relata } \\
\text { se as empresas fazem controle das entradas e saídas de } \\
\text { caixa. Consideram dados como prazo de pagamentos } \\
\text { dos fornecedores. }\end{array}$ \\
\hline \multirow{3}{*}{ Outros Temas } & 23 & \multirow{3}{*}{$\begin{array}{l}\text { As perguntas } 23,24 \text { e } 25 \text {, tratam de outros temas. } \\
\text { Abordam temas como utilização de softwares pelas } \\
\text { empresas, além de verificar a composição do capital da } \\
\text { empresa e o uso de regime de caixa ou competência } \\
\text { das análises financeiras. }\end{array}$} \\
\hline & 24 & \\
\hline & 25 & \\
\hline $\begin{array}{l}\text { Fatores que dificultam a } \\
\text { implantação da } \\
\text { administração financeira }\end{array}$ & 30 & $\begin{array}{l}\text { A questão } 30 \text { está ligada aos fatores que dificultam a } \\
\text { implantação da administração financeira. } \\
\text { Contemplam, de acordo com os entrevistados, quais as } \\
\text { maiores dificuldades de se implantar uma } \\
\text { administração financeira eficiente. }\end{array}$ \\
\hline
\end{tabular}

Fonte: Elaborado pelo autor fundamentado em Cunha (2002, p.37).

\section{ANÁLISE DOS RESULTADOS:}

\subsection{TESOURARIA}

As questões ligadas à tesouraria indicam que grande parte das empresas utilizam mecanismos de controles financeiros. As respostas à questão 2 indicam que todas as empresas possuem controles financeiros de caixa e contas documentados e arquivados. Tal resultado mostrase alinhado aos resultados obtidos por Cunha (2002) que apontaram que, para empresas de pequeno porte este percentual era de $75 \%$ e para as médias e grandes empresa, $100 \%$ delas apresentavam controles financeiros documentados e arquivados. No entanto, a questão 4 demonstra que $75 \%$ das empresas possuem relatórios elaborados a partir dos controles realizados que possam demonstrar sua real situação. Dentre as ferramentas de controle utilizadas, podem-se destacar os demonstrados no Gráfico 1:

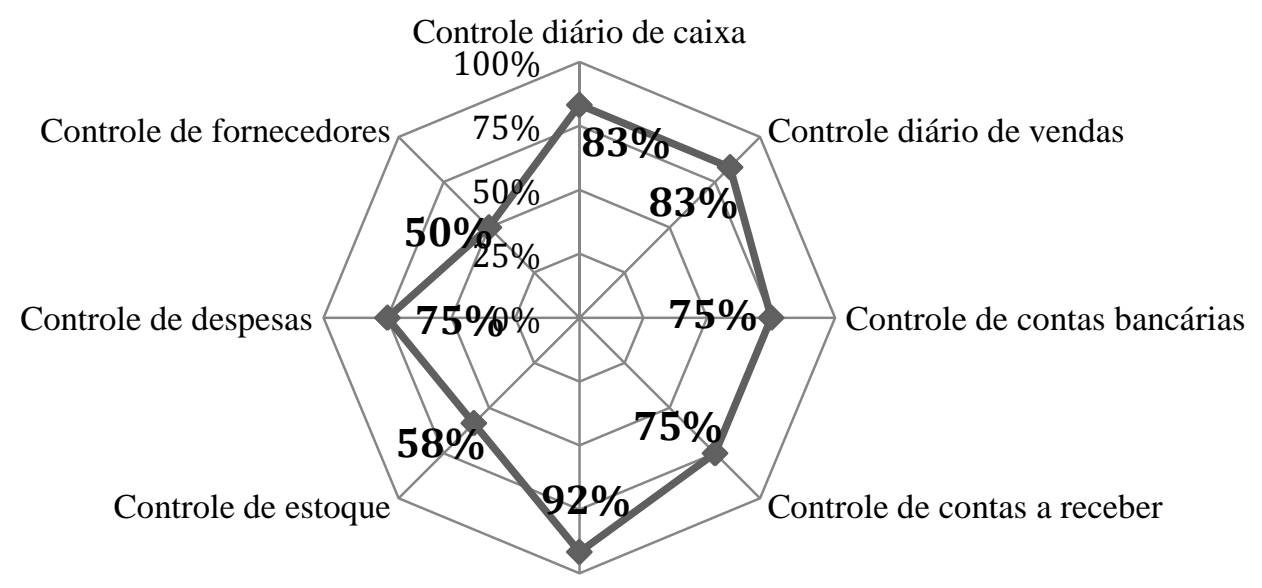

Controle de contas a pagar

\section{$\sim$ Percentual das empresas que utilizam os mecanismos de controle analisados}


Fonte: Elaboração própria

O mecanismo de controle diário de caixa, que é a representação de todas as entradas e saídas de disponível da empresa, é utilizada por 10 (83\%) das empresas entrevistadas, como pode ser observado no Gráfico 1. Mesmo quantitativo das empresas que utilizam controle diário de vendas, $83 \%$. Já os controles de contas bancárias, de contas a receber e de despesas são realizados por $75 \%$ das organizações. $\mathrm{O}$ maior percentual obtido foi em relação ao controle de contas a pagar, cerca de 92\% das empresas entrevistadas. O controle dos estoques é feito por 7 empresas, 58\%, e o menor percentual obtido foi em relação ao controle de pagamentos dos fornecedores, que representam $50 \%$ (6) das respondentes. Resultados semelhantes foram alcançados por Lima e Imoniana (2008). Em seu estudo evidenciaram que, em se tratando de ferramenta de controles gerenciais, taxas de utilização de tais ferramentas variaram de 70,91\% (para o uso de controles de venda) a 90,91\% (para o uso de controles de caixa, contas a pagar e a receber). No sentido oposto, Faria, Oliveira e Azevedo (2012), também analisando empresas do setor de vendas de material de construção, observaram que um percentual muito baixo utilizavam tais ferramentas. Em seus resultados, apenas $10 \%$ das empresas respondentes apontaram o uso de controle de contas a receber e contas a pagar e $5 \%$, controle de custos.

Para facilitar os controles financeiros das empresas, os gestores fazem uso de relatórios detalhados como os de movimentações bancárias, contas a pagar e a receber. O porcentual de empresas que utilizam estes relatórios é demonstrado no Gráfico 2:

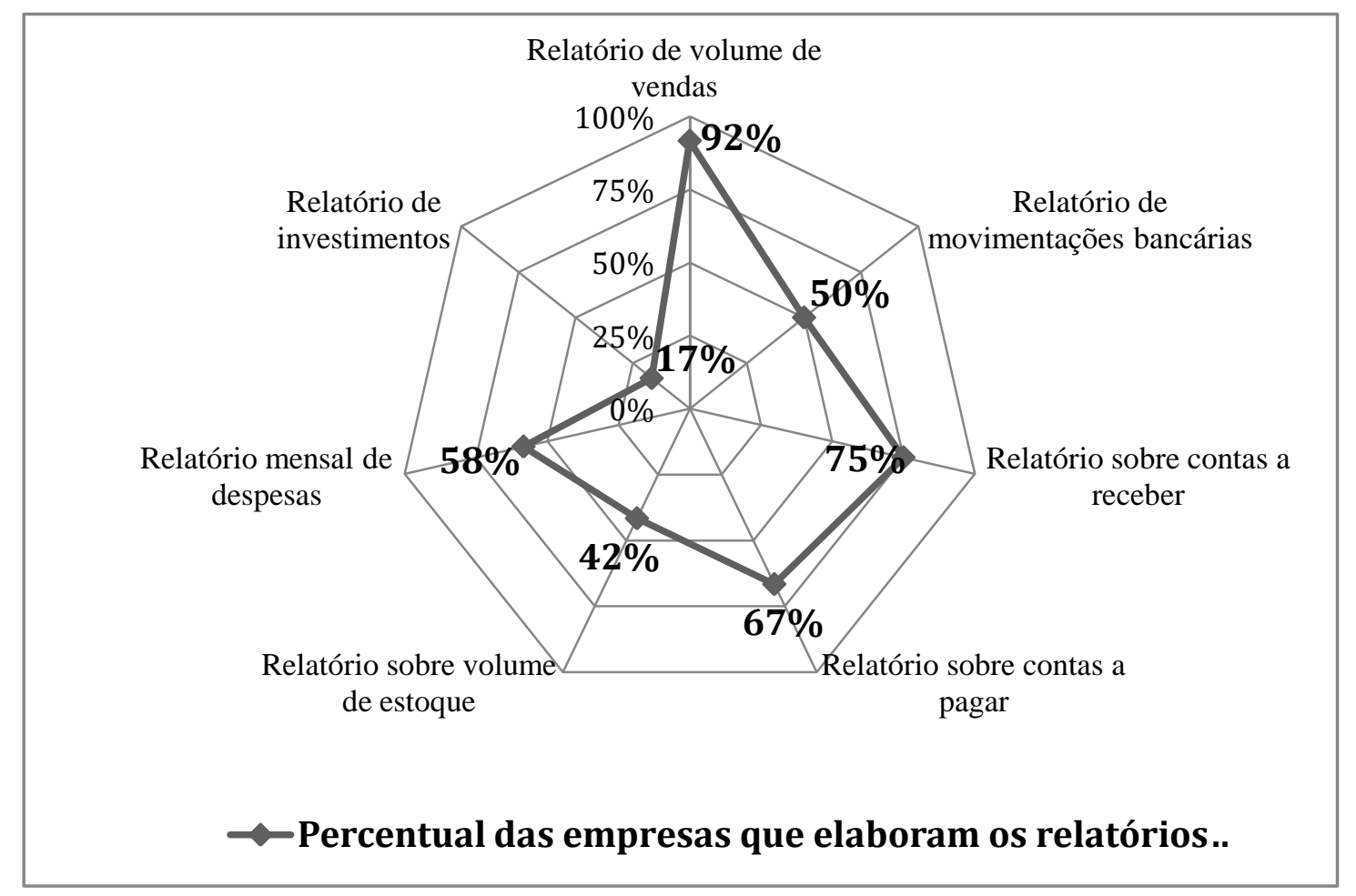

Gráfico 2: Relatórios elaborados pela empresa em percentual e por tipo

Fonte: Elaboração própria.

Segundo o Gráfico 2, o relatório mais utilizado, pelos gestores das empresas de construção civil, é o de volume de vendas, 11 (92\%) do total dos entrevistados. Já a utilização dos relatórios de movimentações bancárias é feita por $50 \%$ gestores das empresas. A quantidade de empresas que declararam fazer uso de relatórios de contas a receber e de contas a pagar foram de $75 \%$ e $67 \%$ respectivamente. Utilizam de relatórios de volumes de estoque $42 \%$ das empresas e de despesas, $58 \%$. No entanto, apenas $17 \%$ utilizam relatórios de investimentos. Pode-se observar que grande parte das empresas faz uso das ferramentas para auxílio da administração financeira. O resultado novamente é contrário ao alcançado por Faria, Oliveira e Azevedo (2012) analisando empresas do 
mesmo setor. Em seus resultados foi possível observar que, para as empresas analisadas, grande parte $(73 \%)$ não utilizavam dos relatórios gerenciais para tomar decisões, sendo que quase a metade delas (48\%) utilizam da experiência do gestor ou de sua intuição para definir as decisões a serem tomadas.

Das empresas entrevistadas, $50 \%$ apresentam prazo de recebimentos dos clientes igual ao prazo de pagamento dos fornecedores, $33,33 \%$ possuem prazo de recebimento maior que o de pagamento e apenas $16,67 \%$ possuem prazo de recebimento dos clientes menor que o prazo de pagamento dos fornecedores. Para as empresas, é melhor quando o prazo de pagamento dos fornecedores é maior que o prazo de pagamento dos clientes, pois desta forma a organização pode pagar os fornecedores com folga financeira.

Outras questões abordadas no questionário estão ligadas ao conhecimento da empresa sobre o pagamento de seus clientes e a formulação de políticas de renegociação de dívidas. Os resultados são demonstrados no quadro abaixo:

\section{Quadro 2: Utilização de controles de contas a receber}

\begin{tabular}{|l|c|c|c|}
\hline \multicolumn{4}{|c|}{ Utilização de controles de contas a receber } \\
\hline Métodos & Sim & Não & Não responderam \\
\hline Conhecimento sobre os atrasos dos clientes & $91,67 \%$ & $0 \%$ & $8,33 \%$ \\
\hline Utilização de políticas de renegociação de dívidas & $83,33 \%$ & $16,67 \%$ & $0 \%$ \\
\hline
\end{tabular}

Fonte: Elaboração própria

Segundo dados do Quadro 2, uma grande porcentagem das empresas conhece o atraso de seus clientes, representando um percentual de $91,76 \%$. No que se refere a utilização de políticas de renegociação de dívidas, pode-se observar que uma grande parte dos entrevistados utilizam desta prática, estes resultados são positivos para a empresa, pois demonstram uma tentativa de diminuir a inadimplência.

A questão 19 trata sobre a utilização de mecanismos de cobrança de contas a receber em atraso. Todas as empresas entrevistadas afirmam que utilizam este mecanismo, sendo que $75 \%$ praticam de forma efetiva e $25 \%$ de maneira esporádica.

\subsection{Demonstrações Financeiras}

As perguntas relacionadas com as demonstrações financeiras indicam se as empresas utilizam ou não os relatórios financeiros. Os resultados são demonstrados no Gráfico 3:

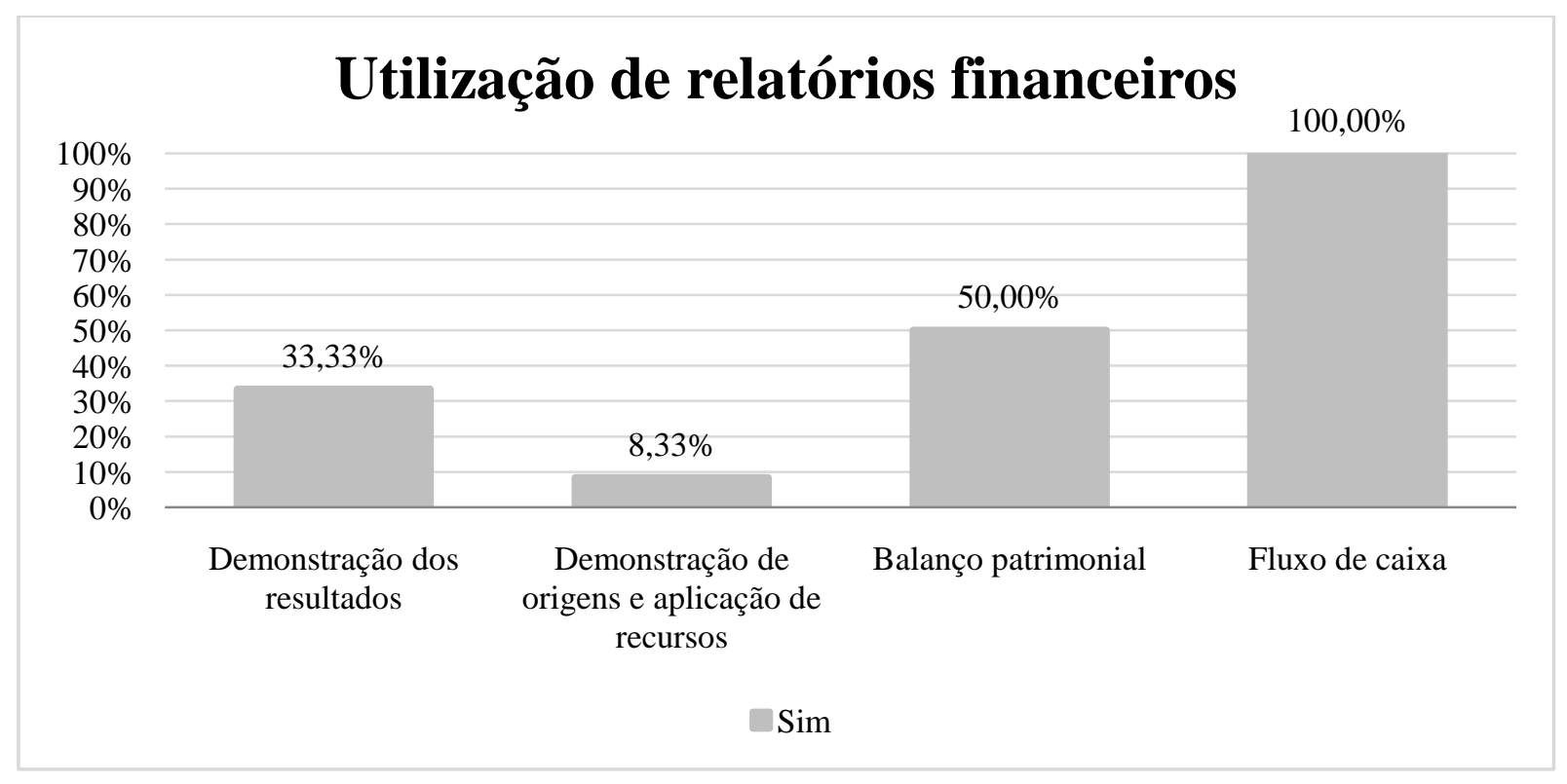

GєCont, v. 4, n. 1, Floriano-PI, Jan-Jun. 2017. 
Gráfico 3: Relatórios utilizados nas análises financeiras

Fonte: Elaboração própria

De acordo com os dados apresentados no Gráfico 3, 33,33\% das empresas utilizam a demonstração dos resultados para a análise financeira. Já a demonstração de origens e aplicação de recursos é utilizada por somente $8,33 \%$ do total das empresas entrevistadas. O Balanço Patrimonial é utilizado por $50 \%$ das empresas, enquanto a demonstração de fluxo de caixa é utilizada por todas as empresas. Os resultados obtidos seguem consoantes aos apontados por estudos como Cunha (2002), Faria, Azevedo e Oliveira (2012), Martins (2015) e Miranda et al. (2015). Nestes estudos, ficou claro a baixa utilização de relatórios como a DRE para o auxílio à tomada de decisão. Martins (2015) observou o uso em apenas 26\% das empresas analisadas, Faria, Azevedo e Oliveira (2012) em $44 \%$ e Cunha (2002), 56\%. Entretanto, Cunha (2002) faz uma resalva de que este percentual refere-se apenas à empresas de pequeno porte, uma vez que todas as empresas de médio e pequeno porte analisadas fazem o uso de tal ferramenta. Para o uso do Fluxo de Caixa, Cunha (2002) também aponta para uma diferença significativa entre os distintos portes das empresas. Em seus resultados $60 \%$ das pequenas, $75 \%$ das médias e $100 \%$ das grandes empresas possuem históricos do Fluxo de Caixa e o utilizam. Já para Faria, Azevedo e Oliveira (2012), Martins (2015) e Miranda et al. (2015) ete percentual cai para 61, 46 e 33\% respectivamente. Neste quesito as empresas analisadas do município de Formiga apresentam uma taxa de utilização maior do que apontado pelos 3 estudos citados.

A questão 7 discorre sobre a consideração dos custos indiretos como décimo terceiro salário, férias e impostos pagos pela empresa. Os resultados das entrevistas mostram que a grande parte das organizações consideram os custos indiretos ou seja $83,34 \%$ do total. Já as empresas que consideram apenas os encargos principais e aquelas que não consideram os custos representam $8,33 \%$ cada.

Outras perguntas feitas para os entrevistados estão ligadas ao cálculo da margem de contribuição e ponto de equilíbrio dos produtos. A margem de contribuição representa o quanto um produto agrega valor na empresa e o ponto de equilíbrio representa o quanto a organização precisa vender para suprir os custos de cada produto. Os resultados são explicados no Quadro 3:

\section{Quadro 3: Métodos de cálculos dos produtos.}

\begin{tabular}{|c|c|c|c|}
\hline Tipos & $\begin{array}{c}\text { Sim, para todos os } \\
\text { produtos }\end{array}$ & $\begin{array}{c}\text { Sim, para alguns } \\
\text { produtos }\end{array}$ & Não \\
\hline $\begin{array}{c}\text { Cálculo da margem de } \\
\text { contribuição }\end{array}$ & $58,33 \%$ & $25 \%$ & $16,67 \%$ \\
\hline Cálculo do ponto de equilíbrio & $41,67 \%$ & $33,33 \%$ & $25 \%$ \\
\hline
\end{tabular}

Fonte: Elaboração própria.

De acordo com o quadro, a maioria das empresas faz uso do cálculo da margem de contribuição e cálculo do ponto de equilíbrio, que são ferramentas muito importantes para a administração financeira, porém, em alguns casos, estes mecanismos são utilizados apenas em alguns produtos.

\subsection{CONTABILIDADE}

O tema contabilidade verifica se a as empresas utilizam os dados contábeis no auxílio da tomada de decisão. Além disso, mostra a frequência em que os relatórios são tratados como uma ferramenta importante.

A pergunta 8 analisa a periodicidade em que os balancetes contábeis são analisados e os resultados indicam que $54,17 \%$ das empresas verificam estes relatórios mensalmente e 45,83\% o fazem anualmente.

O trabalho de Faria, Azevedo e Oliveira (2012) abordou essencialmente a utilização da contabilidade como ferramenta de apoio à decisão em MPEs do setor de vendas de material de 
construção. Neste quesito, o que observaram é que grande parte dos gestores desconhecem as ferramentas da contabilidade e como estas podem auxiliar na tomada de decisão. Puderam observar, também, que há uma visão deturpada por parte dos gestores de que a contabilidade esta voltada praticamente para atender às obrigações legais. Em Formiga, nas empresas analisadas, constatou-se que diversos pontos são passíveis de melhora, no entanto, percebeu-se que, ao contrário do exposto nos resultados de Faria, Azevedo e Oliveira (2012), as empresas conhecem e cerca de metade analisa os relatórios contábeis mensalmente para tomar decisões.

\subsection{AUTO AVALIAÇÃO}

$\mathrm{Na}$ auto avaliação, os entrevistados explicam como está a situação da empresa. A primeira pergunta feita aos administradores das empresas foi com relação à percepção a respeito da administração financeira da empresa. O resultado obtido é demonstrado no Quadro 4:

Quadro 4: Percepção a respeito da administração financeira da empresa.

\begin{tabular}{|c|c|c|c|c|}
\hline $\begin{array}{c}\text { Não há } \\
\text { administração } \\
\text { financeira }\end{array}$ & $\begin{array}{c}\text { Ela existe, de } \\
\text { forma superficial }\end{array}$ & $\begin{array}{c}\text { Existe um bom } \\
\text { acompanhamento } \\
\text { financeiro }\end{array}$ & $\begin{array}{c}\text { A administração } \\
\text { financeira é } \\
\text { excelente }\end{array}$ & Não responderam \\
\hline $0,00 \%$ & $25,00 \%$ & $58,34 \%$ & $8,33 \%$ & $8,33 \%$ \\
\hline
\end{tabular}

Fonte: Elaboração própria

De acordo com o Quadro 4, pode-se observar que na maioria das empresas pesquisadas demonstra ter um bom acompanhamento financeiro, $25 \%$ possuem uma administração financeira de forma superficial e apenas $8,33 \%$ têm uma excelente administração financeira.

Outros aspectos abordados na auto avaliação diz respeito à situação financeira do negócio, à margem de contribuição, ao retorno sobre o investimento total da empresa e à administração financeira do negócio. As respostas dadas pelos entrevistados são descritas no Quadro 5:

Quadro 5: Auto avaliação da empresa

\begin{tabular}{|l|c|c|c|c|}
\hline & Muito bom & Bom & Razoável & Ruim \\
\hline Situação Financeira do negócio & $16,67 \%$ & $66,67 \%$ & $16,67 \%$ & $0,0 \%$ \\
\hline Margem de lucro líquido & $0,0 \%$ & $25 \%$ & $66,67 \%$ & $8,33 \%$ \\
\hline Retorno sobre o investimento total da empresa & $8,33 \%$ & $50 \%$ & $41,67 \%$ & $0,0 \%$ \\
\hline Administração Financeira do Negócio & $16,67 \%$ & $58,33 \%$ & $16,67 \%$ & $8,33 \%$ \\
\hline
\end{tabular}

Fonte: Elaboração própria

No quadro 5, apesar das empresas considerarem a situação financeira boa, a margem de lucro líquido é considerada razoável, mostrando uma divergência nos resultados.

No retorno sobre o investimento, as empresas demonstram um bom retorno, o que condiz com a administração financeira que também é classificada como boa.

\subsection{ADMINISTRAÇÃO FINANCEIRA APROFUNDADA}

$\mathrm{Na}$ Administração Financeira Aprofundada é possível observar se as empresas utilizam relatórios financeiros para avaliação de desempenho e para a análise da viabilidade de investimentos. Segundo resultados da pergunta 9, das empresas entrevistadas, metade delas consideram algum índice financeiro na administração. Já o percentual de empresas que não fazem uso de algum índice representa $41,67 \%$ do total. 
Outro item abordado se refere à utilização de índices financeiros pelas empresas. As respostas obtidas estão detalhadas no Quadro 6:

\section{Quadro 6: Utilização de índices pelas empresas}

\begin{tabular}{|l|c|c|}
\hline & Sim & Não \\
\hline Índice de liquidez & $91,67 \%$ & $8,33 \%$ \\
\hline Índice de endividamento & $91,67 \%$ & $8,33 \%$ \\
\hline Índice de eficiência & $50,00 \%$ & $50,00 \%$ \\
\hline Índice de rentabilidade & $75,00 \%$ & $25,00 \%$ \\
\hline
\end{tabular}

Fonte: Elaboração própria

A partir do Quadro 6, é possível perceber que os índices mais usados pelas empresas são liquidez, que representa a capacidade de pagamento das empresas, e endividamento que significa o porcentual de capital de terceiros em relação ao capital total da organização, sendo o percentual de seu uso $91,67 \%$ cada. Já o índice de eficiência é utilizado por $50 \%$ das empresas e o índice de rentabilidade, que demonstra a capacidade do investimento gerar lucros, é usado por $75 \%$ das empresas. Situação oposta foi observada novamente por Faria, Azevedo e Oliveira (2012). Em seu estudo os autores observaram o Índice de Rentabilidade foi o mais utilizado pelas empresas analisadas, entretanto, apenas $29 \%$ destas faziam o uso do mesmo. Para os Índices de Liquidez e Endividamento os números foram ainda mais baixos, 24 e $17 \%$ respectivamente.

Quando estes índices e os resultados demonstrados nos balancetes não apresentam dados satisfatórios, os gestores em sua maioria $(91,67 \%)$ buscam dados que mostrem as receitas e despesas auferidas e buscam sanar os problemas. Os outros $8,33 \%$ dos gestores cortam gastos e aumentam os preços na tentativa de corrigir problemas.

Em relação ao uso da análise de viabilidade econômica, que é a análise para verificar se um investimento pode gerar lucros para a empresa, é realizada por 58,34\% do total entrevistados. As empresas que não fazem análise de viabilidade econômica representam 33,33\% do total.

Segundo a questão 13, da entrevista realizada com os administradores das empresas de material de construção civil, metade deles afirma fazer projeções na tomada de decisões periodicamente. As empresas que fazem projeções esporadicamente correspondem a 41,67\% do total. As empresas que não responderam compreendem a $8,33 \%$ do total entrevistado. Estas projeções são detalhadas no Quadro 7:

Quadro 7: Projeções realizadas pela empresa

\begin{tabular}{|l|c|c|}
\hline & Não & Sim \\
\hline Necessidades financeiras & $25,00 \%$ & $75,00 \%$ \\
\hline Projeção da demonstração de resultado & $75,00 \%$ & $25,00 \%$ \\
\hline Fluxo de caixa & $50,00 \%$ & $50,00 \%$ \\
\hline
\end{tabular}

Fonte: Elaboração própria

Segundo dados do Quadro 7, o percentual equivalente às empresas que realizam projeções das necessidades financeiras é de $75 \%$. Somente $25 \%$ das empresas fazem projeções da demonstração dos resultados e metade das empresas faz projeções para seu fluxo de caixa.

\subsection{CUSTOS}

O tema ligado aos custos verifica se as empresas consideram estes no momento de calcular os preços à vista quanto a prazo. As respostas dos administradores são detalhadas no Quadro 8:

\begin{tabular}{|l|l|l|}
\hline Sim, considera todos os custos & Sim, considera alguns custos & Não considera os custos \\
\hline
\end{tabular}


Quadro 8: Consideração dos custos na formação do preço de venda

Fonte: Elaboração própria

Nota-se, por meio do Quadro 8, que 41,67\% das empresas consideram todos os custos na formação do preço de venda da mercadoria, $50 \%$ só consideram alguns custos e 8,33\% não consideram nenhum custo.

\subsection{FLUXO DE CAIXA}

O fluxo de caixa das empresas considera todas as entradas e saídas de valores, seja por meio de recebimentos de cliente como por meio de pagamento fornecedores. Em geral, quando as organizações possuem prazo de pagamento superior ao prazo de recebimento, considera-se um fator favorável. O Quadro 9 analisa a utilização do fluxo de caixa feita pelos administradores das empresas entrevistadas:

Quadro 9: Determinação do prazo de pagamento dos fornecedores

\begin{tabular}{|c|c|c|c|}
\hline $\begin{array}{c}\text { Não é feito nenhum } \\
\text { controle }\end{array}$ & O fornecedor determina & $\begin{array}{c}\text { De acordo com a situação } \\
\text { financeira }\end{array}$ & $\begin{array}{c}\text { De acordo com análise de } \\
\text { fluxo de caixa }\end{array}$ \\
\hline $0,00 \%$ & $25,00 \%$ & $33,33 \%$ & $41,67 \%$ \\
\hline
\end{tabular}

Fonte: Elaboração própria

Observa-se, no Quadro 9, que em 25\% das empresas o prazo de pagamento é determinado pelo fornecedor, $33,33 \%$ é determinado de acordo com a situação financeira, e 41,67\% de acordo com a análise do fluxo de caixa.

\subsection{OUTROS TEMAS}

Outros temas abordados no questionário referem-se a dados gerais da empresa, como a utilização de softwares, que é demonstrado pelo Quadro 10:

Quadro 10: Utilização de software para controle e gerenciamento financeiro

\begin{tabular}{|c|c|}
\hline Não & Sim \\
\hline $8,33 \%$ & $91,67 \%$ \\
\hline
\end{tabular}

Fonte: Elaboração própria

De acordo com a pesquisa realizada e os dados informados no Quadro 10, observou-se que $91,67 \%$ das empresas utilizam software para controle e gerenciamento financeiro, e 8,33\% não possuem.

Outra questão perguntada aos administradores é se a empresa utiliza regime de caixa ou competência para registros contábeis, o que é mostrado no Quadro 11:

Quadro 11: Utilização de regime de caixa ou competência

\begin{tabular}{|l|l|l|l|}
\hline Não utiliza & Regime de competência & Regime de caixa & Ambas as metodologias \\
\hline
\end{tabular}




\begin{tabular}{|l|l|l|l|}
$33,33 \%$ & $0,00 \%$ & $41,67 \%$ & $25,00 \%$ \\
\hline
\end{tabular}

Fonte: Elaboração própria

Com base no Quadro 11, nota-se que das empresas pesquisadas 33,33\% não utilizam de regime de caixa nem competência, $41,67 \%$ usam o regime de caixa e $25 \%$ fazem uso de ambas as metodologias. $\mathrm{O}$ regime de competência não é utilizado pelas empresas pesquisadas.

No quesito composição do capital das empresas, estas são divididas conforme ilustrado:

Quadro 12: Composição do capital da empresa

\begin{tabular}{|c|c|c|}
\hline $\begin{array}{c}\text { Maior porcentagem capital } \\
\text { próprio }\end{array}$ & $\begin{array}{c}\text { Maior porcentagem capital de } \\
\text { terceiros }\end{array}$ & Metade de cada \\
\hline $66,67 \%$ & $8,33 \%$ & $25,00 \%$ \\
\hline
\end{tabular}

Fonte: Elaboração própria

A partir do Quadro 12, nota-se que em relação à composição do capital das empresas $66,67 \%$ possuem maior porcentagem de capital próprio, $8,33 \%$ maior porcentagem de capital de terceiros e $25 \%$ metade de cada um.

\subsection{FATORES QUE DIFICULTAM A IMPLANTAÇÃO DA ADMINISTRAÇÃO FINANCEIRA}

Dentre as maiores dificuldades para uma implementação adequada da administração financeira, nas empresas do setor de construção civil, não possuir os recursos necessários (mão de obra qualificada, e/ou sistemas de informações e/ou dinheiro, entre outros), foi apontado por $33,33 \%$ dos entrevistados. Os administradores/gestores que consideram que a maior dificuldade é falta de conhecimento na área de administração financeira correspondem a 16,67\%. Este mesmo percentual representa os administradores que consideram não saber como aplicar o conhecimento na rotina diária da empresa como maior dificuldade. Os prováveis custos de manter um sistema desta natureza é o fator considerado de maior dificuldade para 8,33\% dos entrevistados. Aqueles que não responderam correspondem a $25 \%$ do total. Outra dificuldade, na implementação da administração financeira nas empresas, e apontada pelos gestores, é a falta de informações confiáveis.

\section{CONSIDERAÇÕES FINAIS}

O estudo teve como objetivo verificar se as empresas do setor de materiais de construção da cidade de Formiga utilizam as ferramentas da administração financeira no auxílio da tomadas de decisões. Conforme observado, a maioria das empresas demonstrou que utilizam todas as ferramentas da administração financeira, porém nenhuma se mostrou totalmente satisfeita com os resultados obtidos.

Os dados foram obtidos através de questionários aplicados aos gestores das empresas. Percebe- se que as respostas apresentam contradições, pois as ferramentas da administração financeira dão suporte para que a organização possa alcançar os melhores retornos e trazer rentabilidade para os acionistas ou proprietários, o que não foi apontado pelos administradores.

Os resultados mostram que os mecanismos mais utilizados pelas empresas são controle diário de caixa e controle diário de vendas. Já os relatórios mais utilizados pelas organizações são os de volumes de vendas. Um fator positivo, observado, é que quase a totalidade das empresas tem 
conhecimento sobre os atrasos dos clientes e possuem utilização de políticas de renegociação de dívidas.

Um fator preocupante é em relação à utilização de relatórios para as análises financeiras, pois apenas o demonstrativo de fluxo de caixa é analisado por todas as empresas. Os demais relatórios são usados por pequenas porcentagens dos gestores.

No que tange à auto avaliação das empresas, os resultados foram contraditórios pelo fato de que as empresas afirmam fazer uso das ferramentas da administração financeira, porém a maior parte dos administradores consideram a situação financeira e a administração financeira do negócio como boas. Já a margem de lucro líquido, o retorno sobre o investimento total são considerados como razoáveis. Este resultado demonstra que a empresa pode não estar fazendo o uso das ferramentas de maneira adequada.

Quanto da utilização dos índices, são usados pela metade ou maior parte das organizações pesquisadas. Os índices utilizados são: liquidez, endividamento, eficiência e rentabilidade.

Em relação às dificuldades para a implementação da administração financeira nas empresas, fator indicado pelos gestores é a falta de recursos necessários como mão de obra qualificada, e/ou sistemas de informações e/ou dinheiro.

Para a realização do trabalho, houve grande dificuldade em obter as informações das empresas, além de alguns dados serem imprecisos, o que pode ser observado na pergunta da utilização de regime de caixa ou competência.

Portanto surge a necessidade de novos estudos para verificar se as empresas realmente utilizam estas ferramentas ou se estas estão sendo utilizadas de forma correta. Outro aspecto que pode ser estudado é até que ponto a utilização incorreta das ferramentas pode afetar os resultados das empresas, como no caso da consideração de apenas alguns custos para a formação do preço de venda de metade das empresas entrevistadas.

\section{REFERÊNCIAS}

ABRAMAT - ASSOCIAÇÃO BRASILEIRA DA INDÚSTRIA DE MATERIAIS DE CONSTRUÇÃO. Cenário Macroeconômico, 2009 - 2016. São Paulo: Fundação Getúlio Vargas, 2009.

\section{ABRAMAT - ASSOCIAÇÃO BRASILEIRA DA INDÚSTRIA DE MATERIAIS DE CONSTRUÇÃO. Perfil da Cadeia Produtiva da Construção e da Indústria de Materiais e Equipamentos. São Paulo: Fundação Getúlio Vargas, 2015.}

ANAMACO - Associação Nacional dos Comerciantes de Material de Construção. Informações Gerais (2006). Disponível em: <http://www.anamaco.com.br/premio_top_2006.php>. Acesso em: 07 abr. 2014.

ASSAF NETO, Alexandre. Finanças corporativas e valor. 5. ed. São Paulo: Atlas, 2010.

ATHAR, Raimundo Aben. Introdução á contabilidade. São Paulo: Prentice Hall, 2005.

CAMARGO, Camila. Planejamento financeiro. 2. ed. ver. e atual. Curitiba: Ibpex, 2007.

CAMPELO JR, Aloisio. TOBLER, Rodolpho Guedon. Investimentos produtivos continuam em ritmo lento. [S.1.: s.n.], 2014.

CARAVANTES, Geraldo; PANNO, Cláudia C.; KLOECKNER, Mônica C. Administração: teorias e processos. São Paulo: Pearson Hall, 2005. 
CASALI, Maristela da Silva. A importância da utilização da gestão financeira em microempresas da cidade de Cruz Alta. 2015. TCC (Graduação) - Curso de Ciências Contábeis, Universidade de Cruz Alta, Cruz Alta, 2015.

COSTA, Daniel F. Utilização do Orçamento no Planejamento Tributário de uma Pequena Empresa. Revista Brasileira de Contabilidade, v. 43, n. 206, p. 27-39, 2014

COSTA, D. F., PRADO, J. W., CASTRO JÚNIOR, L. G.; CARVALHO, F. M.. Estimando o Orçamento de Resultado em uma Empresa Varejista: uma abordagem por meio de vetor autorregressivo - VAR. Exacta - EP, São Paulo, v. 12, n. 3, p. 279-191, 2014.

CUNHA, Marco Antônio Nascimento da. O perfil da administração financeira das pequenas e médias empresas. 2002. 95 f. Dissertação (Mestrado) - Curso de Administração, Fgv, Rio de Janeiro, 2002.

DIEESE. Estudo setorial da Construção 2012. São Paulo: Dieese, 2013.

DUARTE JÚNIOR, Antônio Marcos. Gestão de riscos para fundos de investimentos. São Paulo: Prentice Hall, 2005.

FARIA, Juliano Almeida e; OLIVEIRA, Murilo Silva; AZEVEDO, Tania Cristina. A utilização da contabilidade como ferramenta de apoio à gestão nas micro e pequenas empresas do ramo de comércio de material de construção de Feira de Santana/BA. Revista da Micro e Pequena Empresa (FACCAMP), v. 6, n. 2, p. 89-106 , 3 set. 2012.

FERNANDES, Adriano; GONÇALVES, João Paulo Guerreiro. Análise do perfil da gestão financeira realizada pelas micro e pequenas empresas da cidade de Itajubá. In: Simpósio de Excelência em Gestão e Tecnologia, 8, 2011, Resende. Anais... Resende: Aebd, 2011. p. 1 - 15.

FERREIRA, José Antonio Stark. Contabilidade de custos. São Paulo: Pearson Prentice Hall, 2007.

FUNDAÇÃO JOÃO PINHEIRO. Dataviva. Disponível em: http://pt.dataviva.info/. Acesso em: 10 de janeiro de 2016.

GITMAN, Lawerence Jeffrey. Princípios de administração financeira, 12. ed. São Paulo: Pearson Prentice Hall, 2010.

GONÇALVES, Robson. Comércio exterior competitividade e produtividade. [S.1.: s.n.], 2014.

GUPTA, A.. Sales forecasting \& market potential: best practices in India. International Journal of Advanced Marketing and Research, v. 1, n. 1, p. 1-7, 2013.

CENTRO DE EXCELÊNCIA EM VAREJO DA FGV-EAESP. Análise Setorial - Materiais de Construção. [S.1.: s.n.], 2012.

IBGE. Pesquisa Anual da Indústria da Construção - PAIC 2011. Disponível em:< http://www.ibge.gov.br/home/estatistica/pesquisas/pesquisa_resultados.php?id_pesquisa=27>. Acesso em: 20 nov. 2014

LEMES JÚNIOR, Antônio Barbosa. Administração financeira: princípios, fundamentos e práticas trabalhistas - 2. ed. Rio de Janeiro: Elsevier, 2005. 
LIMA, A. N. ; IMONIANA, J. O. Um estudo sobre a importância do uso das ferramentas de controle gerencial nas micro, pequenas empresas e médias empresas industriais no município de São Caetano do Sul. Revista da Micro e Pequena Empresa (FACCAMP), v. 1, p. 3, 2008.

MARTINS, Amanda. A utilização das ferramentas da gestão financeira nas empresas: análise das micro e pequenas empresas da cidade de Pato Branco no sudoeste do Paraná. 2015. 67 f. TCC (Graduação) - Curso de Ciências Contábeis, Utfpr, Pato Branco, 2015.

MASCARENHAS, Sidnei Augusto. Metodologia científica. São Paulo: Pearson Education do Brasil, 2012.

MIRANDA, L. B. S. et al. Ferramentas administrativas utilizadas nas micro e pequenas empresas: uma análise realizada no centro comercial da cidade de Viçosa - MG. Revista do IEEE América Latina, v. 1, p. 39-52, 2016

OLIVEIRA, H. C. et al. A Gestão Financeira como instrumento de maximização de resultados das empresas. Revista Eletrônica de Ciências Empresariais. Ano 03, n. 06, Jan. a Jun.de 2010.

PLÁCIDO, L.D.G.; SANTOS, L. M.; MURTA, L. N. A tecnologia da informação é importante no controle financeiro de micro e pequenas empresas? Uma análise de múltiplos casos em Minas Gerais. Revista da Micro e Pequena Empresa (FACCAMP), v. 9, p. 51-64, 2015.

ROCHA, Águida Garreth Ferraz. Planejamento e gestão estratégica. São Paulo: Pearson Education Brasil, 2012.

RODRIGUES, Chrystian Marcelo. Análise de crédito e risco. Curitiba: Ibpex, 2011.

RODRIGUES, J. P. L.; MELO, M. A.; LEONE, R. J. G. Gestão financeira em micro e pequenas empresas: um estudo no setor supermercadista de Mossoró-RN. Connexio - Revista Científica da Escola de Gestão e Negócios, v. 5, p. 125-140, 2016.

ROSS, Stephen A. Princípios da administração financeira. 2. ed. 7. São Paulo: Atlas, 2008.

SANTOS, Edno Oliveira dos. Administração financeira da pequena e média empresa, 2. ed. São Paulo: Atlas, 2010.

SERVIÇO BRASILEIRO DE APOIO ÀS MICRO E PEQUENAS EMPRESAS - SEBRAE. Sobrevivência das empresas no Brasil - Coleção estudos e pesquisas. Brasília, 2013.

SILVA, Davy A.; SANTOS, Maria E.; COSTA, Daniel F.. A utilização do modelo de Holt-Winters na elaboração de um orçamento de resultado de uma cooperativa de crédito rural. Revista de Contailidade do Mestrado em Ciências Contábeis da UERJ (online), v. 21, n. 1, p. 39 - 56, 2016.

SOARES, Keila Graciela Ribeiro et al. Gestão Financeira em micro empresas familiares: um estudo na indústria moveleira de Santa Cruz de Minas - MG. XIX Congresso de pós-graduação da UFLA. Lavras, 2010.

VIAPIANA, Cláudio. Fatores de sucesso e fracasso da micro e pequena empresa. Universidade Federal de Santa Catarina, Centro Sócio-Econômico. Santa Catarina, 2000. 
APÊNDICE A - QUESTIONÁRIO APLICADO

\section{Dados da empresa:}

Empresa:

Ano de fundação: $\mathrm{N}^{\circ}$ de funcionários:

Classificação da empresa quanto ao tamanho:

Entrevistado: Cargo:

Quantos anos de experiência em gerenciamento?

1. Qual a sua percepção a respeito da administração financeira da sua empresa?

( ) Não há uma administração financeira na minha empresa;

( ) Ela existe, mas de forma superficial;

( ) Existe um bom acompanhamento financeiro na minha empresa;

( ) A administração financeira da minha empresa é excelente.

2. A empresa apresenta controles financeiros que são documentados e arquivados?

( ) Não ( ) Sim

3. Se a resposta anterior foi sim, assinale abaixo todos os mecanismos de controle utilizados:
( ) Controle diário de caixa
( ) Controle diário de vendas
( ) Controle de contas bancárias
( ) Controle de contas a receber
( ) Outros: Especifique:

( ) Controle de contas a pagar

( ) Controle de estoque

( ) Controle de despesas

( ) Controle de fornecedores

4. A empresa possui relatórios elaborados a partir dos controles realizados que possam demonstrar a real situação da empresa?
( ) Não
( ) $\operatorname{Sim}$

5. Se a resposta anterior foi sim, assinale quais desses relatórios são elaborados pela empresa:
( ) Relatório de volume de vendas
( ) Relatório sobre volume de estoque
( ) Relatório de movimentações bancárias
( ) Relatório mensal de despesas
( ) Relatório sobre contas a receber
( ) Relatório de investimentos
( ) Relatório sobre contas a pagar
( ) Outros relatórios: Especifique:

6. Quais dos relatórios abaixo a empresa utiliza em suas análises financeiras:

( ) Demonstração de resultados / Apuração de lucro

( ) Demonstração de origens a aplicação de recursos

( ) Balanço patrimonial

( ) Fluxo de caixa

( ) Outros relatórios: Especifique:

7. Em suas análises financeiras a empresa considera os custos indiretos como $13^{\circ}$ salário, férias, impostos, e outros?

( ) Não considera ou considera de acordo com a saída dos recursos do caixa

( ) Considera os encargos principais

( ) Considera todos os encargos, de acordo com a legislação e sindicato, e/ou provisiona os recursos. 
8. Com que periodicidade são analisados os balancetes contábeis?
( ) Não são analisados
( ) Mensalmente
( ) Trimestralmente
( ) Anualmente
( ) Semestralmente

9. Em suas análises financeiras a empresa considera algum índice financeiro para sua administração?

( ) Não ( ) Sim

10. Se a resposta anterior foi sim, assinale quais índices utiliza:

( ) Índice de liquidez (Liquidez corrente, liquidez seca, etc)

( ) Índice de Endividamento (Grau de endividamento, composição do endividamento, etc)

( ) Índice de Eficiência (Giro dos estoques, prazo médio de recebimento, etc)

( ) Índice de Rentabilidade (Margem de lucro sobre as vendas, ROI, ROA, etc)

( ) Outros relatórios: Especifique:

11. Caso os resultados demonstrados nos balancetes contábeis não sejam satisfatórios, qual a medida tomada pela organização?

( ) Busca dados que mostram as despesas e receitas, e planeja com cautela para sanar esse problema;

( ) Corta gastos e aumenta o preço, sem ao menos planejar;

( ) Não toma nenhuma decisão e aguarda outros períodos mais rentáveis.

12. Para realizar algum tipo de investimento a empresa faz alguma análise de viabilidade econômica?

( ) Não

( ) Sim. Realiza estudos de viabilidade através de metodologias tradicionais (TIR, Pay-Back, VPL, etc.)

13. A empresa faz projeções que auxiliam no acompanhamento de sua situação financeira e na tomada de decisões?
( ) Não
( ) Sim,esporadicamente
periodicamente ) Sim,

14. Se a resposta anterior foi sim, assinale quais projeções são realizadas:

( ) Necessidades e/ou disponibilidades financeiras

( ) Projeção da Demonstração de Resultado

( ) Fluxo de caixa

( ) Outros: Especifique:

15. Como é, em média, o prazo de recebimento dos clientes em relação ao prazo de pagamento dos fornecedores?

( ) O prazo de recebimento é maior que o de pagamento.

( ) Em geral, ambos apresentam o mesmo prazo.

( ) O prazo de recebimento dos clientes é menor que o prazo concedido pelos fornecedores.

16. A empresa faz o cálculo da margem de contribuição dos produtos vendidos?

( ) Sim, a margem de contribuição é calculada para todos os produtos.

( ) Sim, porém só alguns produto tem a margem de contribuição calculados.

( ) Não. 
17. A empresa calcula o ponto de equilíbrio dos produtos vendidos?

( ) Sim, todos os produtos são calculados.

( ) Sim, porém só alguns produtos tem o ponto de equilíbrio calculados.

( ) Não.

18. A empresa conhece os atrasos de pagamento de seus clientes?

( ) Não ( ) Sim

19. Se a resposta foi positiva, há mecanismos de cobrança de contas a receber em atraso?

( ) Sim, o controle é feito de forma efetiva.

( ) Sim, o controle é feito de forma de forma esporádica.

( ) Não, a empresa não possui mecanismo de cobranças.

20. A empresa conta com políticas de renegociação de dívidas?

( ) Não ( ) Sim

21. A empresa considera os custos como: taxa de juros, despesas com cobranças (nos casos de pagamentos recebidos com atrasos) na formação do preço de venda à prazo?

( ) Sim, todos os custos são levados em consideração.

( ) Sim, mas somente alguns deles são colocados nos cálculos.

( ) Não, o preço à prazo é o mesmo do preço à vista, portanto nenhum custo é considerado.

22. Como é determinado o prazo de pagamento de fornecedores?

( ) Não é feito nenhum controle

( ) Quem determina é o fornecedor

( ) De acordo com a situação financeira para os prazos dados pelo fornecedor

( ) De acordo com análise do fluxo de caixa e/ou estratégia de capital de giro

23. A empresa possui algum software para o controle e gerenciamento financeiro?

( ) Não ( ) Sim

24. A empresa faz uso do regime de caixa ou competência em suas análises financeiras?

( ) Não utiliza

( ) Regime de caixa

( ) Regime de competência

( ) Ambas as metodologias

25. Como é composto o capital da empresa?

( ) Maior porcentagem de capital próprio.

( ) Maior porcentagem de capital de terceiros.

( ) Em média, possui 50\% de capital próprio e 50\% de capital de terceiros.

26. Como você considera atualmente a situação financeira de seu negócio?
( ) Muito boa
( ) Ruim
( ) Boa
( ) Péssima
( ) Razoável

27. Como você considera a margem de lucro líquido de sua empresa?
( ) Muito boa
( ) Ruim
( ) Boa
( ) Péssima
( ) Razoável 
28. Como você considera o retorno sobre o investimento total em sua empresa?
( ) Muito boa
( ) Ruim
( ) Boa
( ) Péssima
( ) Razoável

29. Como você considera a administração financeira de seu negócio?

( ) Muito boa

( ) Boa

( ) Razoável

\author{
( ) Ruim \\ ( ) Péssimo
}

30. Indique quais as maiores dificuldades para uma implantação adequada de administração financeira nas empresas do setor de construção civil (enumere do mais importante (1), ao menos importante (5)):

( ) Falta de conhecimento na área de administração financeira

( ) Não saber como aplicar o conhecimento na rotina diária da empresa

( ) Os prováveis custos de manter um sistema desta natureza

( ) Não possuir os recursos necessários (mão de obra qualificada e/ou sistemas de informações e/ ou dinheiro, entre outros)

( ) Outros - Quais: 
